\title{
Clinical Reasoning: Progressive Proximal Weakness in a 61-Year-Old Man
}

Margaret Yu, MD, Mireille Bitar, MD, Michael Collins, MD, and Jinny Tavee, MD

Neurology ${ }^{\circledR}$ 2022;98:122-127. doi:10.1212/WNL.0000000000013000

\author{
Correspondence \\ Dr. Yu \\ margaret.yu@ \\ northwestern.edu
}

\section{Section 1}

A 61-year-old man presented with a 6-week history of painless progressive weakness. Initially, he had difficulty climbing stairs. Three weeks later, he could not reach overhead to change light bulbs and had exertional shortness of breath. He choked on solids and liquids resulting in a 20$\mathrm{lb}$ weight loss. Review of systems was negative for diurnal variation, ptosis, diplopia, speech changes, rash, sensory changes, pseudobulbar affect, autonomic symptoms, or recent infection.

History included hypertension, hyperlipidemia, and nonischemic cardiomyopathy diagnosed 2 years earlier. Echocardiography demonstrated ejection fraction of $20 \%-25 \%$ and dilated left ventricle. Cardiac MRI showed transmural enhancement of the inferolateral wall; the initial endomyocardial muscle biopsy revealed hypertrophic myocytes and minimally increased interstitial fibrosis without inflammation. The cardiomyopathy etiology remained idiopathic, and he was started on aspirin and atorvastatin. Atorvastatin was stopped after his progressive weakness began. His mother had systemic lupus erythematosus, and he had a 30-pack-year history of tobacco use but no alcohol or illicit drug use.

A clinical examination showed symmetric proximal weakness with a Medical Research Council (MRC) grade of $4 / 5$ in the upper and 3/5 in the lower extremities. Distal strength was intact. Neck flexion and extension were $4 / 5$ and $4+/ 5$, respectively. The weakness was not fatigable. Tone was normal without atrophy or fasciculations. No bulbar muscle weakness or dysarthria noted. Deep tendon reflexes were $2+$ throughout with flexor plantar responses bilaterally. $\mathrm{He}$ had a waddling gait, but the remainder of the examination, including cranial nerves, sensory modalities, and cerebellar testing, was normal. There were no rashes or other dermatologic findings.

\section{Questions for Consideration:}

1. Where should the lesion be localized?

2. What is the differential diagnosis?

\section{GO TO SECTION 2}

From the Department of Neurology (M.Y.), Northwestern Feinberg School of Medicine; Department of Pathology (M.B.), Northwestern Feinberg School of Medicine, Chicago, IL; Department of Neurology (M.C.), Medical College of Wisconsin, Wauwatosa, WI; and Division of Neurology (I.T.), National Jewish Health, Denver, CO.

Go to Neurology.org/N for full disclosures. Funding information and disclosures deemed relevant by the authors, if any, are provided at the end of the article. 


\section{Section 2}

His proximal weakness and lack of central findings (hyperactive reflexes, Hoffman sign, Babinski sign, and spasticity) point toward the peripheral nervous system. Pure motor findings further localize the lesion to the anterior horn cell, peripheral nerve, neuromuscular junction, or muscle.

The symmetric and proximal distributions of weakness make motor neuron disease less likely. Presentation is not typical of neuromuscular junction pathology such as myasthenia gravis (ocular findings were spared despite severity of generalized weakness and dysphagia) or Lambert-Eaton myasthenic syndrome (lack of dysautonomia or postexercise facilitation). Peripheral nerve localization is possible, but both proximal and distal weaknesses would be expected, and most are hyporeflexic.

In symmetric proximal weakness without sensory symptoms, primary muscle diseases are high on differential. Myopathies can either be inherited or acquired. The rapidly progressive course at age 61 years is suggestive of an acquired etiology, whereas a chronic condition with young onset points toward an inherited etiology. With acute to subacute onset, toxic and inflammatory myopathies are on the differential. Common toxic etiologies include cholesterollowering medications, corticosteroids, amiodarone, and colchicine. Inflammatory etiologies include dermatomyositis, polymyositis, antisynthetase syndrome, anti-HMGCR (3-hydroxyl-3-methylglutaryl-coenzyme A reductase) myopathy, anti-SRP (signal recognition particle) myopathy, and sarcoidosis. Infectious etiology is less likely, given no history of fever, chills, night sweats, or recent travel. His previous idiopathic nonischemic cardiomyopathy raises concern for myopathies with cardiac involvement, namely, muscular dystrophies, inflammatory myopathies (e.g., dermatomyositis and autoimmune necrotizing myopathy), and amyloidosis.

\section{Question for Consideration:}

1. Which investigations narrow the differential? 


\section{Section 3}

He had an elevated troponin I (peak $6.47 \mathrm{ng} / \mathrm{mL}$ ) and elevated creatine kinase $(\mathrm{CK})$ of $8,889 \mathrm{IU} / \mathrm{L}$. A comprehensive metabolic panel was unremarkable except for elevated liver enzymes (ALT 254 and AST 189 units/L), which can be seen in both muscle and liver diseases. Other laboratory examinations for liver pathology such as alkaline phosphatase, bilirubin, and albumin were not abnormal. The liver appeared unremarkable on imaging. Renal function, electrolytes, complete blood count, thyroid-stimulating hormone, serum protein electrophoresis with immunofixation, antinuclear antibody, autoimmune profile, hepatitis panel, and HIV antigen/antibody were unrevealing. Serum and urine light chain analyses were also unrevealing, not suggestive of primary (AL type) amyloidosis. Urinalysis displayed trace protein and a moderate amount of blood. Testing for myoglobinuria was not performed at this time. EMG showed evidence of a generalized irritable myopathy characterized by diffuse fibrillation potentials and small, polyphasic motor units in a proximal to distal gradient.

Repeat cardiac catheterization showed negative results for ischemic disease then. A second endomyocardial biopsy revealed interstitial fibrosis and noncaseating granulomas (NCGs) consistent with cardiac sarcoidosis, which was further supported by CT-PET findings of patchy heterogeneous radiotracer uptake within the myocardium. Congo red stain was negative for amyloid, and acid-fast bacilli and fungal stains showed negative results. Serum angiotensin-converting enzyme, although nonsensitive or specific, was elevated at 105 unit/L, which supported the diagnosis of cardiac sarcoidosis in conjunction with the biopsy findings. The patient was started Neurology.org/ $\mathrm{N}$ with $30 \mathrm{mg}$ of prednisone daily.

\section{Question for Consideration:}

1. Is this presentation typical for sarcoidosis myopathy? 


\section{Section 4}

Asymptomatic muscle involvement is seen in $50 \%$ of patients with sarcoidosis ${ }^{1}$ but clinically apparent myopathy in $<2 \%$ of cases. ${ }^{2}$ The most common form of muscle involvement is a chronic insidiously progressive myopathy characterized by remissions and exacerbations. ${ }^{3,8}$ Muscle weakness is typically proximal-predominant with occasional involvement of trunk, neck, facial, bulbar, and respiratory muscles. ${ }^{4} \mathrm{CK}$ is typically normal, and EMG demonstrates a myopathic pattern with a variable frequency of abnormal spontaneous activity. $^{3}$
Muscle biopsy typically shows an active inflammatory process with noncaseating granulomas with predominantly CD4-positive lymphocytic infiltration. Treatment and prognosis are ill-defined. In a review of 19 cases of acute sarcoidosis myositis, all patients presented with proximal-predominant muscle weakness and only 3 patients had dysphagia with bulbar weakness. EMG showed evidence of a myopathy in 11 of the 11 patients with a mean CK of 2,293 IU/L. ${ }^{5}$

\section{Question for Consideration:}

1. Because the patient's presentation is atypical for sarcoidosis myopathy, what further investigations should be considered?

GO TO SECTION 5 


\section{Section 5}

Muscle biopsy of the left deltoid obtained before treatment initiation showed scattered necrotic and regenerating fibers with paucity of inflammation localized to necrotic fibers (Figure 1). No NCGs were seen. Patient's MRI demonstrated diffuse edema and postcontrast enhancement within the paraspinal musculature and psoas muscles, which is a common finding in inflammatory myopathies. ${ }^{7}$

Anti-SRP antibody was positive with a titer greater than 100 (reference range $<11$ ). Anti-HMGCR antibody and antisynthetase antibody were negative. He was diagnosed with anti-SRP myopathy-sarcoidosis overlap syndrome.

Treatment began with IV methylprednisolone ( $1 \mathrm{~g}$ daily for 3 days), followed by IV immunoglobulin (IVIG) $2 \mathrm{~g} / \mathrm{kg}$ over 4 days. Within days of treatment, there was strength and mobility improvement. He was discharged with oral corticosteroids, outpatient rituximab infusions, and monthly IVIG treatment. Owing to his underlying cardiac status and concerns for volume overload, rituximab and IVIG were discontinued. He maintains on methotrexate and low-dose corticosteroids. At 3 months follow-up, his CK normalized and his neurologic examination was normal except for trace hip flexion weakness. His cardiac status did not improve.

\section{Discussion}

This is a rare case of overlap anti-SRP myopathy and sarcoidosis syndrome. Although a necrotizing myopathy has rarely been reported with sarcoidosis myopathy, the presence of high-titer anti-SRP antibody and phenotype support the diagnosis of an overlap syndrome, defined as multiple distinct autoimmune diseases occurring together.

Figure Hematoxylin and Eosin-Stained Section Showing Few Necrotic Myofibers Invaded by Macrophages (200x magnification)

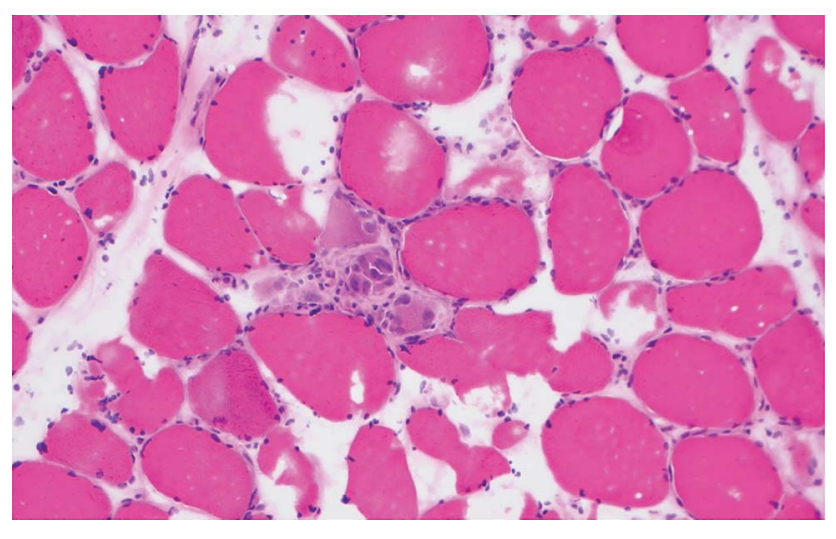

Anti-SRP myopathy was initially classified as a severe form of polymyositis. In 2003, the European Neuro Muscular Center (ENMC) International Workshop on Idiopathic Inflammatory Myopathies established diagnostic criteria recognizing immune-mediated necrotizing myopathies (IMNMs), also known as necrotizing autoimmune myopathies (NAMs), as separate entities among the idiopathic inflammatory myopathies based on studies noting distinct clinical phenotype, histopathology, serology, and treatment options. ${ }^{6}$ In the most recent 2017 ENMC classification criteria, IMNMs, including anti-SRP myopathy, are now characterized by rapidly progressive proximal muscle weakness and markedly elevated creatinine kinase $(\mathrm{CK})$ levels ${ }^{7,10}$

Onset age is typically after the fourth decade, peaking in the sixth decade, with anecdotal cases of juvenile onset reported. ${ }^{8}$ Progression is usually subacute over 5-6 months and can be manifested as a rapid progression over 5-6 weeks, although chronic insidious presentation mimicking muscular dystrophy can occur. ${ }^{7}$ Patients typically have proximal symmetric weakness affecting legs more than the arms with MRC grade of $\leq 3 / 5$ in $50 \%-63 \%$ of cases. ${ }^{8,9}$ Neck weakness and dysphagia are frequent manifestations. ${ }^{8,9}$ Skin involvement is rare in anti-SRP myopathy, and studies do not show increased risk of malignancy. 8,9 Interstitial lung disease (ILD) is noted in approximately $20 \%$ of cases. ${ }^{9}$ Cardiac involvement shows cardiac conduction abnormalities but not cardiomyopathy in case reports. ${ }^{8}$

CK levels are markedly elevated to more than $1000 \mathrm{IU} / \mathrm{L}$ in most patients. ${ }^{7}$ EMG demonstrates evidence of a myopathy with positive sharp waves and/or fibrillation potentials in $48 \%$ of patients. ${ }^{8}$ Muscle biopsy usually reveals a necrotizing myopathy indicated by prominent muscle fiber necrosis and regeneration and a paucity of inflammation similar here. ${ }^{9}$ The molecular mechanism of anti-SRP myopathy is not fully elucidated and has not yet been demonstrated in animal models. However, the presence of membrane attack complexes on the surface of nonnecrotic muscle fibers in IMNMs suggests that antibody/complement-mediated cell death may underlie myofiber toxicity. ${ }^{7}$

In anti-SRP myopathy, treatment is currently based on expert opinion and small case series. Because some cases may remain refractory to conventional monotherapy, recent consensus statement recommended IV/oral corticosteroids along with the addition of IVIG or other immunosuppressive agents such as methotrexate or rituximab. ${ }^{10}$ In severe cases, rituximab may be added. Prognosis is variable, but treatment is usually lifelong.

\section{Study Funding}

The authors report no targeted funding

\section{Disclosure}

The authors report no disclosures relevant to the manuscript. Go to Neurology.org/ $\mathrm{N}$ for full disclosures. 
Appendix Authors

\begin{tabular}{lll}
\hline Name & Location & Contribution \\
\hline $\begin{array}{l}\text { Margaret } \\
\text { Yu, MD }\end{array}$ & $\begin{array}{l}\text { Department of Neurology, } \\
\text { Northwestern Feinberg School } \\
\text { of Medicine }\end{array}$ & $\begin{array}{l}\text { Drafting/revision of the article } \\
\text { for content, including medical } \\
\text { writing for content }\end{array}$ \\
\hline $\begin{array}{l}\text { Mireille } \\
\text { Bitar, MD }\end{array}$ & $\begin{array}{l}\text { Department of Pathology, } \\
\text { Northwestern Feinberg School } \\
\text { of Medicine, Chicago, IL }\end{array}$ & $\begin{array}{l}\text { Drafting/revision of the article } \\
\text { for content, including medical } \\
\text { writing for content }\end{array}$ \\
\hline $\begin{array}{l}\text { Michael } \\
\text { Collins, } \\
\text { MD }\end{array}$ & $\begin{array}{l}\text { Department of Neurology, } \\
\text { Medical College of Wisconsin, }\end{array}$ & $\begin{array}{l}\text { Drafting/revision of the article } \\
\text { for content, including medical } \\
\text { writing for content }\end{array}$ \\
\hline $\begin{array}{l}\text { Jinny } \\
\text { Tavee, } \\
\text { MD }\end{array}$ & $\begin{array}{l}\text { Division of Neurology, } \\
\text { National Jewish Health, }\end{array}$ & $\begin{array}{l}\text { Drafting/revision of the article } \\
\text { for content, including medical } \\
\text { Denver, CO }\end{array}$ \\
\hline
\end{tabular}

\section{References}

1. Myers GB, Gottlieb AM, Mattman PE, Eckley GM, Chason JL. Joint and skeletal muscle manifestations in sarcoidosis. Am J Med. 1952;12(2):161-169.
2. Silverstein A, Siltzbach LE. Muscle involvement in sarcoidosis. Asymptomatic myositis, and myopathy. Arch Neurol. 2006;21(3):235-241.

3. Wolfe SM, Pinals RS, Aelion JA, et al. Myopathy in sarcoidosis: clinical and pathologic study of four cases and review of the literature. Semin Arthritis Rheum. 1987;17(4): 300-306.

4. Maeshima S, Koike H, Noda S, et al. Clinicopathological features of sarcoidosis manifesting as generalized chronic myopathy. J Neurol. 2015;262(4): 1035-1045.

5. Ost D, Yeldandi A, Cugell D. Acute sarcoid myositis with respiratory muscle involvement: case report and review of the literature. Chest. 1995;107(3): 879-882.

6. Hoogendijk JE, Amato AA, Lecky BR, et al. 119th ENMC international workshop: trial design in adult idiopathic inflammatory myopathies, with the exception of inclusion body myositis, 10-12 October 2003.

7. Pinal-Fernandez I, Casal-Dominguez M, Mammen AL. Immune-mediated necrotizing myopathy. Curr Rheumatol Rep. 2018;20(4):21.

8. Suzuki S, Nishikawa A, Kuwana $\mathrm{M}$ et al. Inflammatory myopathy with anti-signal recognition particle antibodies: case series of 100 patients. Orphanet J Rare Dis. 2015; $10: 61$.

9. Pinal-Fernandez I, Mammen AL. Spectrum of immune-mediated necrotizing myopathies and their treatments. Curr Opin Rheumatol. 2016;28(6): 619-624.

10. Allenbach Y, Mammen AL, Benveniste O, Stenzel W. 224th ENMC International Workshop:clinic-sero-pathological classification of immune-mediated necrotizing myopathies, 14-16 October 2016, Zandvoort, The Netherlands. Neuromuscul Disord. 2018;28(1):87-99.

\section{Subspecialty Alerts by E-mail!}

Customize your online journal experience by signing up for e-mail alerts related to your subspecialty or area of interest. Access this free service by clicking on the "My Alerts" link on the home page. An extensive list of subspecialties, methods, and study design choices will be available for you to choose from-allowing you priority alerts to cutting-edge research in your field!

\section{Sign Up for the AAN's Axon Registry}

The AAN encourages its US members to show their interest in participating in the Axon Registry ${ }^{\circledR}$ by signing up today.

Use the Axon Registry to:

- Simplify reporting requirements under MACRA's Quality Payment Program and avoid penalties while reducing your administrative burden

- Meet your MOC Part IV requirements and waive up to eight credits of Part II Self-Assessment

- Choose from 22 AAN neurology-specific quality measures that fit your practice

- Use data to understand your practice and identify where improvements can be made to patient care

- Manage your patients at a population level; look at a specific group of patients based on conditions, risk factors, demographics or outcome

- Demonstrate your value to payers when negotiating reimbursement

- Enjoy multi-year, fee-free access when you sign the agreements and integrate your EHR with the registry

Learn more at AAN.com/view/Axon and send your questions to registry@aan.com. 


\section{Neurology}

\section{Clinical Reasoning: Progressive Proximal Weakness in a 61-Year-Old Man \\ Margaret Yu, Mireille Bitar, Michael Collins, et al.}

Neurology 2022;98;122-127 Published Online before print October 21, 2021

DOI 10.1212/WNL.0000000000013000

This information is current as of October 21, 2021

$\begin{array}{ll}\begin{array}{l}\text { Updated Information \& } \\ \text { Services }\end{array} & \begin{array}{l}\text { including high resolution figures, can be found at: } \\ \text { http://n.neurology.org/content/98/3/122.full }\end{array} \\ \text { References } & \text { This article cites } 9 \text { articles, } 0 \text { of which you can access for free at: } \\ & \text { http://n.neurology.org/content/98/3/122.full\#ref-list-1 } \\ \text { Subspecialty Collections } & \text { This article, along with others on similar topics, appears in the } \\ & \text { following collection(s): } \\ & \text { All Clinical Neurology } \\ & \text { http://n.neurology.org/cgi/collection/all_clinical_neurology } \\ & \text { All Neuromuscular Disease } \\ & \text { http://n.neurology.org/cgi/collection/all_neuromuscular_disease } \\ & \text { Autoimmune diseases } \\ & \text { http://n.neurology.org/cgi/collection/autoimmune_diseases } \\ & \text { Muscle disease } \\ & \text { http://n.neurology.org/cgi/collection/muscle_disease } \\ & \text { Information about reproducing this article in parts (figures,tables) or in } \\ & \text { its entirety can be found online at: } \\ & \text { http://www.neurology.org/about/about_the_journal\#permissions } \\ \text { Permissions \& Licensing } & \text { Information about ordering reprints can be found online: } \\ & \text { http://n.neurology.org/subscribers/advertise }\end{array}$

Neurology ${ }^{\circledR}$ is the official journal of the American Academy of Neurology. Published continuously since 1951, it is now a weekly with 48 issues per year. Copyright (C 2021 American Academy of Neurology. All rights reserved. Print ISSN: 0028-3878. Online ISSN: 1526-632X.

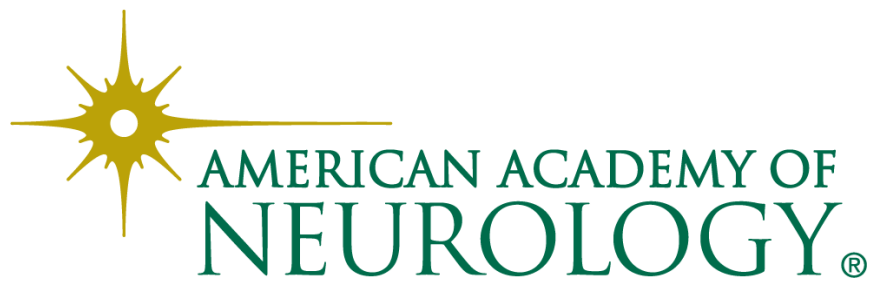

